\title{
COMMUNICATIONS
}

\section{HEREDITARY DEGENERATIVE MACULAR LESIONS WITH INFLAMMATORY SIGNS AND LATE VISUAL DISTURBANCE*}

\author{
BY \\ C. M. J. VELZEBOER \\ Amsterdam
}

THE ophthalmoscopic appearances of hereditary degenerative macular lesions vary greatly, as do the functional disturbances produced, the time of onset, the course, and the mode of inheritance.

Behr (1920), finding the time of onset fairly constant in the members of one sibship, classified hereditary macular degeneration on this basis, starting with the congenital cases (Best, 1905), proceeding to the juvenile and adolescent types (Stargardt, 1909, 1913, 1919), and ending with the senile.

The time of onset, however, is difficult to estimate precisely if the visual disturbance is not serious or starts late in the course of the disease. It is now known that the disease may start at different ages even in one sibship. Furthermore, the great variety of lesions that may be encountered in any one of Behr's groups does not assist our understanding of the site and nature of a given lesion.

Sorsby, Mason, and Gardener (1949) proposed an anatomical classification of the lesions: those localized primarily in the choroid (central choroidal sclerosis), those in Bruch's membrane (angioid streaks) or in the neuroepithelium (central retinal dystrophy), and possibly also those in the ganglion cells or the vascular retinal supply.

Two important points should be borne in mind:

(1) Comparison of the functional disturbance with the ophthalmoscopical aspect of a lesion, especially in early cases, can help to locate the primary site of the lesion;

(2) In some degenerative lesions the macular appearance is not very characteristic in early cases. In central choroidal sclerosis (Sorsby and Crick, 1953) the early stage showed light exudative changes and/or fine pigmentary mottling, whereas in the older patients the picture was typical. In other heredo-degenerative lesions, e.g. vitelliform macular degeneration, the early stages are the most typical.

If the lesions can be studied at different stages covering two or three generations more complete information as to their type can be obtained. 
The following report concerns eight cases covering three generations in one family (Fig. 1).

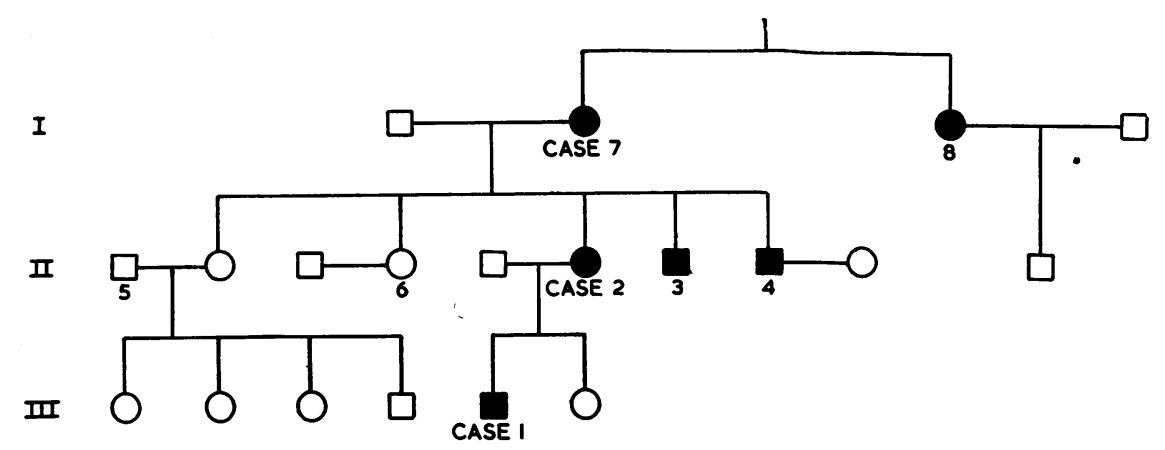

Fig. 1.-Family tree.

The investigation was prompted by the findings in Cases 2 and 3, but the cases are presented below in order of age, beginning at the youngest.

(1) A 5-year-old boy, son of Case 2, was first seen by us in 1958 at the age of 3 years. There were no visual complaints. He was in excellent health and apparently had no intellectual defects. The macular area in both eyes showed a round, yellowish, slightly prominent patch, homogeneous in structure. There was only very slight pigmentary mottling. Outside this affected area the retina was normal, and the optic disc and vessels were normal. The visual acuity was $5 / 6$ in the right eye, and 1/2 in the left. The case was diagnosed as vitelliform macular degeneration (Figs 2 and 3, opposite).

(2) A 28-year-old woman, mother of Case 1, suddenly complained about a dark spot in front of the right eye in April, 1958. This eye had always been less good than the left and had a history of squint. The visual acuity was $1 / 6$ in the right eye and $5 / 5$ in the left. The media were clear, with no opacities in the vitreous. In the right macula there was a sharply-outlined depigmented area with scattered clumps of pigment (Fig. 4, opposite), which strongly resembled a scar following choroiditis.

In the left eye the macular area had been transformed into a round cyst, with a central clump of pigment and a crumbly, hypopyon-like, white mass below (Fig. 5, opposite).

The visual fields, plotted with the double projection campimeter (Hagedoorn and van den Bosch, 1955), revealed a paracentral scotoma in each eye (Figs 6 and 7, overleaf, p. 643). Red-green differentiation was slightly disturbed in both eyes with no anomaly in blue-green differentiation. There was an abnormal anomaloscope equation resembling that seen in protanomaly.

The original diagnosis was one of central choroiditis. There was an inflammation in the left maxillary sinus, from which a polyp was removed. 2 weeks later, however, the brother of the patient (Case 3) was admitted to hospital with sudden visual deterioration and macular lesions in both eyes, and the diagnosis of Case 2 was changed to heredomacular degeneration at the "scar" stage in the right eye, and at the exudative stage in the left eye.

The condition remained static until November, 1958, when a central defect like a macular hole was noted in the left eye.

In November, 1960, the visual acuity was $1 / 3$ in the right eye and $5 / 5$ in the left; the fundus of the right eye remained unchanged, but in the left macula there was a round, 


\section{HEREDITARY DEGENERATIVE MACULAR LESIONS}

Fig. 2. -

Case 1, right eye.

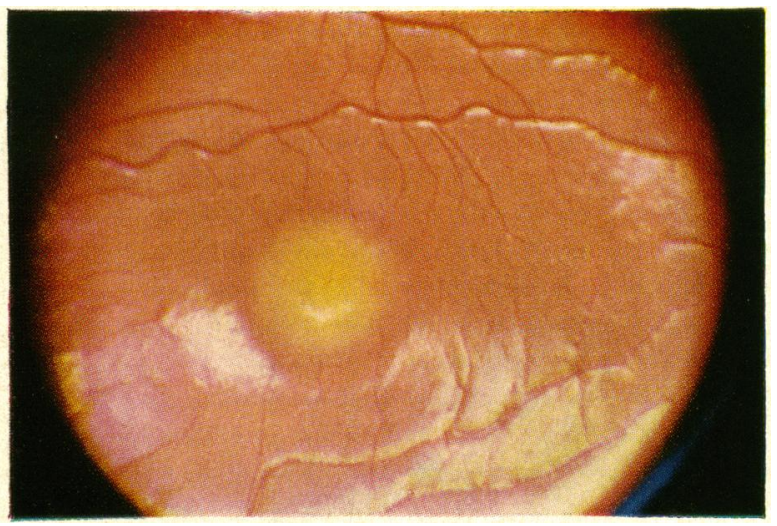

Fig. 3.-

Case 1, left eye.

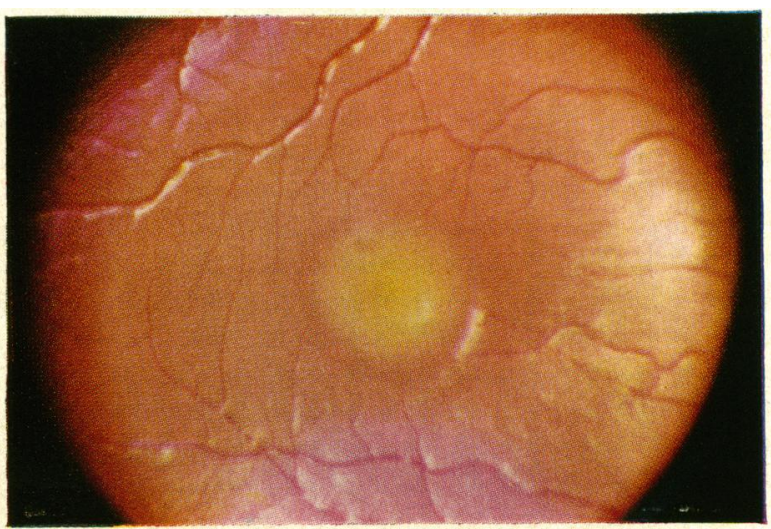

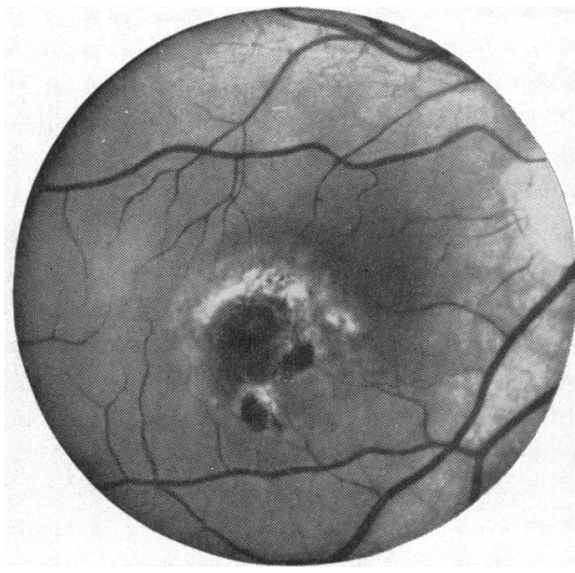

Fig. 4.-Case 2, right eye.

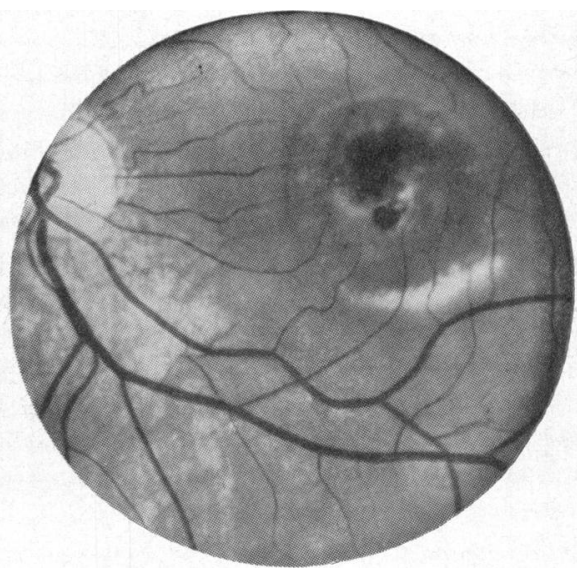

Fig. 5.-Case 2, left eye. 


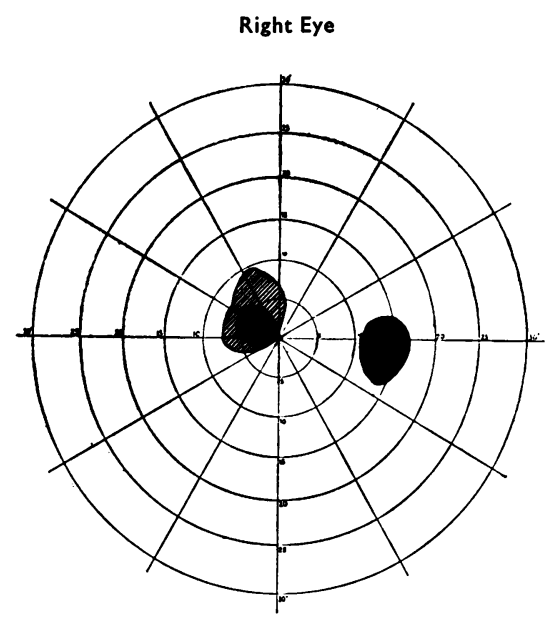

Fig. 6.-Case 2, visual field, right eye. Black: $10^{\prime}$ white. 1600 lux. Shaded: $30^{\prime}$ red, 1600 lux.

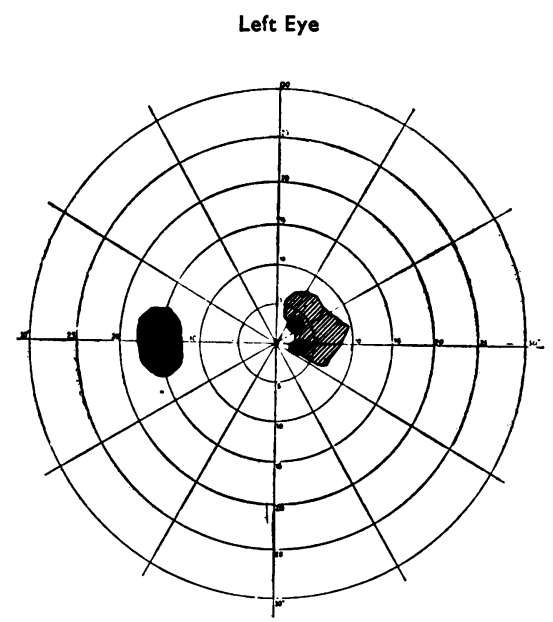

FIG. 7.-Case 2, visual field, left eye. Black: $10^{\prime}$ white, 1600 lux. Shaded: $30^{\prime}$ red, 1600 lux.

depigmented area with a white, sharp, and slightly prominent border. There was no longer any cyst, but the inferior crumbly mass with a horizontal upper border remained unchanged. There was no choroidal sclerosis, and outside the macular area the retina was completely normal.

The patient had also had a 5-year-old daughter, in whom no abnormality was found.

(3) A man aged 22, brother of Case 2, had had no visual complaints until 2 days before he was admitted to hospital (May, 1958) when he noted a dark spot in front of his left eye. The visual acuity was 5/4 in the right and 1/4 in the left. The vitreous was clear. In both eyes the macula showed a sharply-outlined area of pigmentary dystrophy. In the left eye the retina at this point was less translucent (Fig. 8). In the right eye a central red centre area suggested a normally-pigmented foveal region (Fig. 9) surrounded by a whitish substance. Outside the macula the retina was normal. There was no choroidal sclerosis.

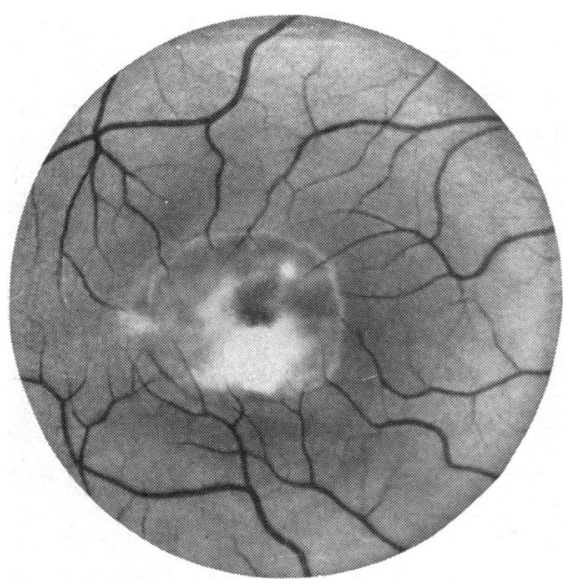

Fig. 8.-Case 3, left eye.

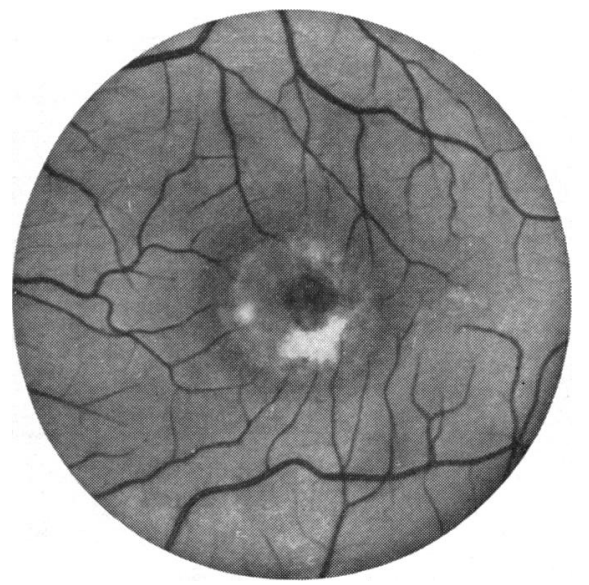

Fig. 9.-Case 3, right eye. 
The visual field of the right eye showed only a small paracentral scotoma for red and in the left eye a scotoma extended over the centre of the field (Fig. 10). The colour vision of the right eye was slightly disturbed in the red-green as well as in the blue-green regions.

In the succeeding months the visual acuity of the left eye improved to $5 / 4$, the scotoma contracted (Fig. 11), and the retina over the central area became translucent again, but in June, 1960, the visual acuity deteriorated to $1 / 6$, and the macula showed some oedema. Some weeks later the "inflammatory" signs had subsided, and in November, 1960, the visual acuity was again $5 / 4$ in both eyes.

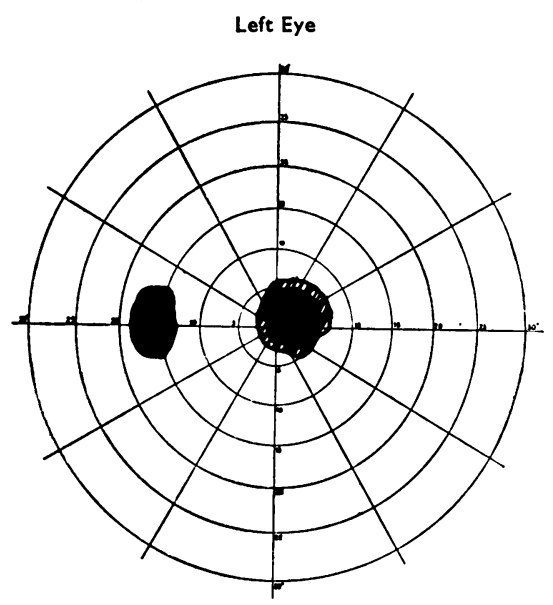

Fig. 10.-Case 3, visual field, left eye, showing central scotoma. Black: $30^{\prime}$ red, 1600 lux. Shaded: 30 ' red, 400 lux.

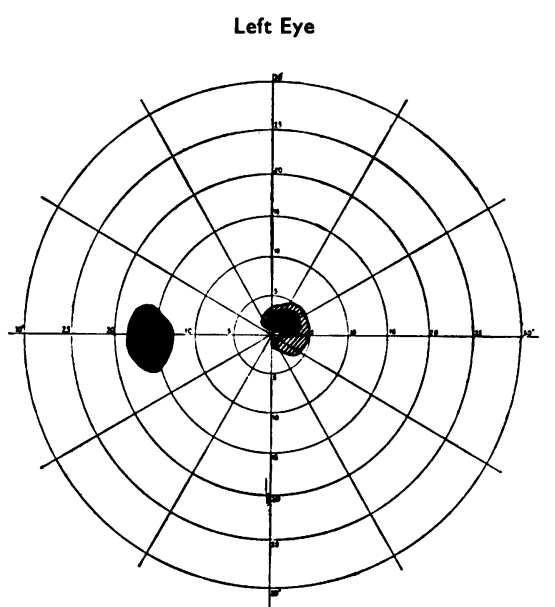

Fig. 11.-Case 3, visual field, left eye, showing contracted scotoma. Black: $30^{\prime}$ red, 1600 lux. Shaded: $30^{\prime}$ red 400 lux.

(4) A man aged 24, brother of Case 2, had always had a weak right eye. The visual acuity was $1 / 3$ in the right eye and 5/5 in the left. The media were clear. Depigmented areas were seen in both maculae; in the right eye there was a pigment mass in the centre of the area (Fig. 12), and in the left eye the depigmented area was traversed by a line of pigment (Fig. 13).

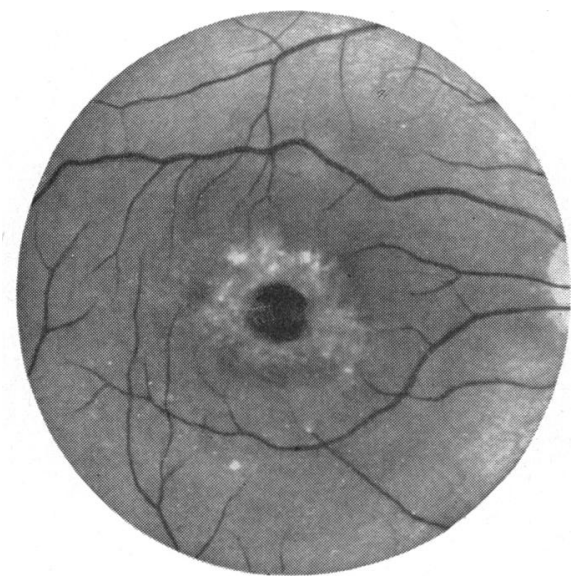

Fig. 12.-Case 4, right eye.

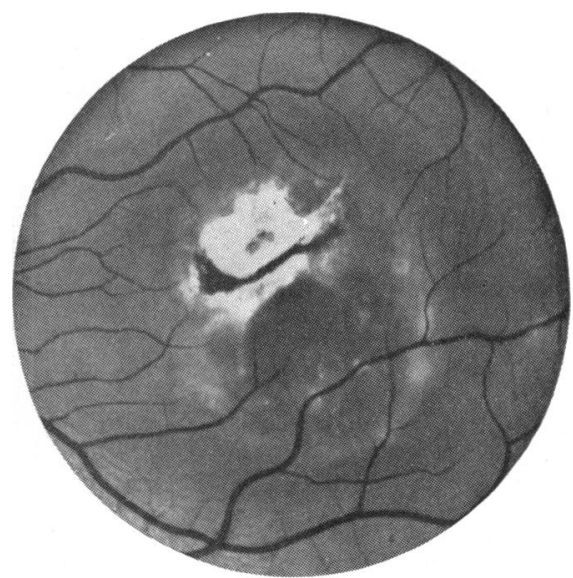

FIG. 13.-Case 4, left eye. 
There was no choroidal sclerosis. Outside the affected area the retina was normal except for some very small depigmented spots near the macula. The optic disc was normal.

There was a paracentral scotoma in each eye, and slight disturbance of colour vision, more pronounced in the red-green than in the blue-green regions.

(5) A woman aged 32, sister of Case 2, had never had any visual complaints. The visual acuity was $6 / 4$ in each eye with visual fields intact, and colour vision undisturbed. The macular areas of the fundi were normal. She had four children, the eldest of whom was mentally deficient, but all had normal fundi and good vision.

(6) A woman aged 27, sister of Case 2, had no visual complaints. The visual acuity was $5 / 4$ in both eyes with no scotomata. In the macular area of both eyes, there was a fine mottling of pigment but it was not definitely pathological in appearance. The colour vision was undisturbed.

(7) A woman aged 57, mother of Case 2, had always had a weak right eye, but did not recall the time of onset. The visual acuity was $2 / 60$ in the right eye and 5/5 in the left. In the right eye the fundus showed a sharply outlined area of pigmentary dystrophy in the macula, with a dense white mass in the peripheral part of the area (Fig. 14). There was no choroidal sclerosis. In the left eye the macular region showed only some white spots in the central part (Fig. 15). The visual field showed a central scotoma in the right eye, but was normal in the left eye. The colour vision was undisturbed.

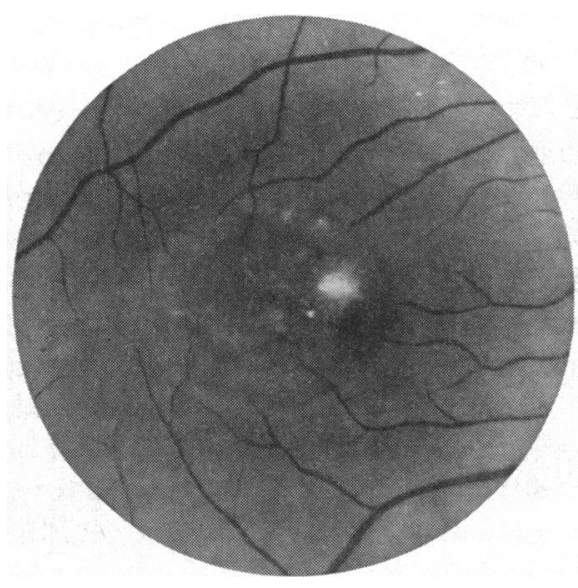

Fig. 14.-Case 7, right eye.

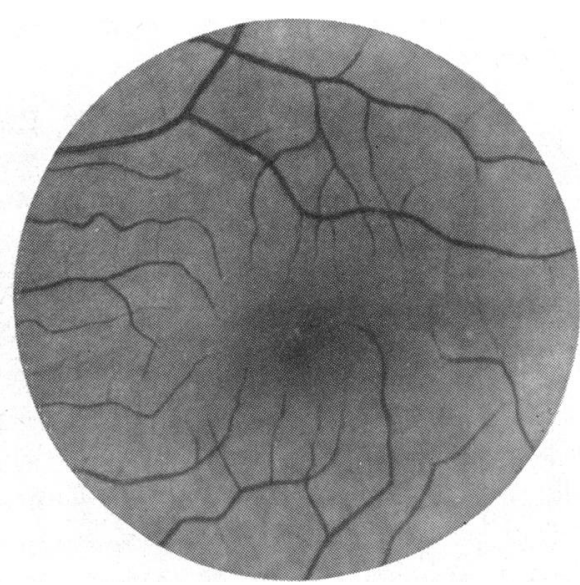

Fig. 15.-Case 7, left eye.

(8) A woman aged 62, sister of Case 7, aunt of Case 2, had had visual complaints for the preceding 11 years. The visual acuity was $1 / 4$ in the right eye and $1 / 10$ in the left. The vitreous of both eyes revealed synchysis scintillans, more pronounced in the right eye. The macular region of both eyes revealed slight pigmentary disturbance, but because of the dense synchysis scintillans this could not be accurately determined. There was a paracentral scotoma in the right eye, and a central scotoma was perhaps present in the left but could not be plotted exactly. 
A 20-year-old son of Case 8 showed no fundus abnormality. The visual acuity was $3 / 4$ in each eye and the visual fields and colour vision were undisturbed.

The parents of Cases 7 and 8 were not consanguineous.

\section{Discussion}

The typical picture of vitelliform macular degeneration, the yellow cyst with fine pigmentary mottling, cannot be mistaken for any other anomaly. One of its outstanding features is that visual function is surprisingly unimpaired.

Vitelliform degeneration in the younger members of this family corresponded to macular lesions of another type in two older generations. A similar family with six cases in three generations was described by Falls (1949). The youngest patients, 3 and 7 years old, showed typical vitelliform degeneration with good vision. In the earlier generation pigmentary disturbance and colloid bodies were found in the macular region, and in the oldest members much pigmentation was seen, as well as glial proliferation and colloid bodies.

Although vitelliform macular degeneration has been described in older patients by Behr (1920), Kurz (1947), and Friedenwald and Maumenee (1951), and seemed in their cases to be a constant condition, it is generally regarded as an early stage of juvenile hereditary degeneration (Zanen and Rausin, 1950, 1951; Klien, 1950).

The evolution was described by Zanen (1953) in a report of a 14-year-old boy with a typical vitelliform cyst in the macula. 3 years later the cyst had been replaced by a greyish pigmented zone, the visual acuity remaining unchanged.

According to Klien (1958), the breaking up of the homogeneous yellow substance in the cyst leads to visual disturbance and later the cyst ruptures.

This process is clearly demonstrated in our Case 2 , in which the condition was originally diagnosed as choroiditis. The scar in the right eye matched the final stage of the process in the left eye: a cyst with "hypopyon" of a white and crumbly mass. Huysmans (1940) described an identical picture in a patient aged 39, the other members of whose family showed cysts or abnormal pigmentation but had good vision.

In our Case 2 visual disturbance was of recent date and probably coincident with an alteration in the fundus picture with the breaking down of the homogeneous yellow cyst. In the following months the fundus remained practically unchanged, the macular hole noted about 6 months later being probably due to the rupture of the cyst. After $2 \frac{1}{2}$ years there was a depigmented area similar to that in the other eye, the prominent borders and a remnant of the white mass being still reminiscent of the preceding "active stage". During the whole process the visual acuity had remained unchanged (5/5) with a paracentral scotoma. 
The same picture of an "active stage" was seen in our Case 3, in which visual disturbances had arisen only shortly before. In both eyes a sharply depigmented area was observed. In the left eye, with the visual disturbance, the retina was slightly opaque, but there was no cyst. The course of the disease in the left eye showed definite improvement in function together with a "clearing up" of the retina, but a second deterioration in vision occurred 2 years later, when the retina was again oedematous. There were no haemorrhages or exudates, and again the inflammatory signs subsided and vision improved from $1 / 6$ to $5 / 4$.

In one of Behr's cases improvement was mentioned but it was not possible to give objective data.

Sorsby (1940) described two sibships (the $\mathrm{M}$ and $\mathrm{N}$ families) in whom the macular degeneration had an exudative aspect. Deterioration and improvement during and after pregnancy were mentioned but no data were given. Sorsby pointed out the exudative character of haemorrhages that may be encountered in the early stages of degeneration. This was especially clear in the families with central choroidal sclerosis. According to Sorsby different types of reaction, pigmentary mottling, colloid bodies, oedema, and exudates may represent different stages of the same process.

Such acute deterioration and subsequent improvement of vision provide a dramatic feature in a degenerative process which is usually slowly progressive.

It is known that in the course of hereditary retinal degeneration the lesion does not only change and increase in intensity and extent but may also change in character. It is not to be expected that the reaction of a tissue in a degenerative process will always be the same; "dramatic" developments may occur, such as the bursting of a swollen cyst, or a sudden decrease in vascular supply. Instead of progressing gradually the ophthalmoscopic appearance may remain the same for a certain period, after which a sudden and rapid change may occur. In these acute episodes the appearance is similar to that of an inflammatory process, like oedema or haemorrhage.

As pointed out above, the time of onset was considered to be the most constant feature in a family with hereditary retinal degeneration, and various types were classified on this basis. The time of onset, however, is sometimes difficult to assess. In Cases 2 and 3, of the second generation, visual disturbance started in the early twenties. In Case 4, the right eye had "always" been weak. In the older generation Case 7 had had one bad eye "since childhood", and Case 8 said that the visual disturbance had started at about the age of 50 . It is evident, therefore, that classification on this basis may lead to confusion.

Heredity is a prominent feature, and in our cases was dominant, but the mode of inheritance may vary. Juvenile macular degeneration of Stargardt's type is recessive, but dominant types were described by Sorsby and Wren, 1960 (good vision) and Vail and Stroch, 1959 (progressive functional loss). Falls (1949) remarked that different modes of inheritance need not 
denote different clinical entities. Even in a clear-cut clinical picture, such as primary degeneration of the retina, dominant and recessive modes of inheritance are found.

We agree with Sorsby that different types of macular degeneration can best be understood on the basis of anatomy. This involves four tissues*:

Neuro-epithelium, rods, and cones; Pigment epithelium; Bruch's membrane; Choriocapillaris.

In advanced cases the primary lesion is difficult to determine. These four tissues are mutually dependent, and degeneration of one influences the anatomy and function of another.

In early cases the fundus picture, together with visual function, provide evidence about the primary damage:

(1) Neuro-epithelium.-Early visual disturbance is certain to be present. The cases of Steinmetz, Ogle, and Rucker (1956) must be classed in this group since the visual disturbances started at about 6 years of age, although no abnormality was seen ophthalmoscopically before the age of 35 . In this sibship there was loss of the whole cone system.

The cases of Stargardt $(1909,1913,1916)$ also belong to this group. Vision deteriorated early and pigmentary disturbances followed.

Records of pathological investigation are rare, but Klien (1958) described a macular lesion in a woman aged 60; the lesion in the neuro-epithelium was more extensive than in the pigment epithelium so that this case too belongs to this group.

(2) Pigment Epithelium.-Visual disturbance is either absent or minimal and starts late in the course of the disease, the fundus abnormalities being detected earlier. There may be great variety in the fundus pictures.

The pigment epithelium reacts to noxious agents, degeneration, or malnutrition with a variety of different patterns:

A. Atrophy and depigmentation;

B. Proliferation and heavy pigmentation (e.g. Sorsby and Wren, 1960);

C. Deposit of lipids or hyaline. In circulatory disturbances the pigment epithelium cells may proliferate and become phagocytic, containing lipid. Asayama and Tagak (1937) reported on lipids in the pigment epithelium in xerosis and hemeralopia.

The patients of our family belong to this group, the six cases in three generations representing different stages of a degenerative process of the pigment epithelium.

The presence of the yellow cyst with fine pigment granules suggests two possibilities:

(a) An area of swollen pigment cells filled with a homogeneous substance;

(b) A space filled with material between the pigment epithelium and Bruch's membrane.

In both instances the pigment epithelium may be regarded as the primary site. Koyanagi (1934) described the pathology of cases with nephritic retinopathy; a

* In this classification degeneration of the retinal ganglion cells is not taken into consideration. In such degenerations, like amaurotic idiocy and Spielmeyer-Vogt's disease, lesions elsewhere in the nervous system are always a severe complication. The pathology of such cases is well known. 
sub-retinal substance had been secreted by the pigment epithelium, the cells of which were filled with drops of a hyaline substance.

In most cases the yellow cyst changes in the course of the disease, and either bursts or disperses. The bursting of cells and chemical influences are responsible for the inflammatory appearance and the acute onset of visual complaints. Atrophy and pigment proliferation follow as the end-stage of the process. As stated above, the neuro-epithelium and pigment epithelium are interdependent. Advanced degeneration and atrophy of the pigment epithelium leads to disturbance of the neuro-epithelium, and hence to visual disturbance, which starts late in the course of the disease.

(3) Bruch's Membrane.-This localization is evident in angioid streaks. Cases of Doyne's hereditary colloid degeneration may also be classed in this group, like the colloid bodies found by Treacher Collins (1913) in a pathological investigation. In most cases, however, the colloid bodies are a secondary reaction to a lesion outside Bruch's membrane. Moreover it is still uncertain whether colloid bodies arise as a result of abnormal secretion of the pigment epithelium or because of a degeneration of Bruch's membrane.

(4) Choriocapillaris.-This is the primary site in cases of Sorsby's central choroidal sclerosis. Ashton (1953) found the choroidal vessels in the central area to be totally absent. No sclerosis was seen and the ciliary vessels were intact. Apart from the choroidal changes the outer retinal layers were absent, so that they may be regarded as secondary to the vascular atrophy in the choroid. The exudates and haemorrhages in the early stage support the idea of a primary vascular disturbance, the nature of which, as in other degenerative processes, remains obscure.

\section{Summary}

Dominant hereditary macular degeneration in six persons from three generations of one family is described.

The fundus of the youngest patient, Case 1, aged 3, showed vitelliform macular degeneration, with good vision in each eye.

In the next generation (Cases 2-6) visual disturbance started in the twenties but was less severe than was to be expected from the extensive macular lesions. In these patients acute deterioration was coupled with an inflammatory appearance of the macular lesions.

In the oldest generation (Cases 7 and 8) only pigment disturbances were seen.

A comparison of the retinal function with the fundus picture, especially in early cases, may furnish evidence about the origin of the lesion from one of four possible sites:

(1) The neuro-epithelium in cases with early functional loss (e.g. Steinmetz, Ogle, and Rucker, 1956).

(2) The pigment epithelium, with late and less severe functional disturbance (e.g. our own cases). 
(3) Bruch's membrane, angioid streaks, and possibly Doyne's hereditary colloid degeneration.

(4) The choriocapillaris, as in the central choroidal sclerosis of Sorsby and Crick (1953).

\section{REFERENCES}

Ashton, N. (1953). Brit. J. Ophthal., 37, 140.

Asayama, R., and Takagi, A. (1937). Klin. Mbl. Augenheilk., 98, 162.

BEHR, C. (1920). Ibid., 65, 465.

Best, F. (1905). Z. Augenheilk., 13, 199.

COllins, E. TREACHER (1913). Ophthalmoscope, 9, 537.

Dollfus, M. A. (1948). Bull. Soc. franç. Ophtal., 61, 344.

FALLS, H. F. (1949). Amer. J. hum. Genet., 1, 96.

Friedenwald, J. S., and Maumenee, A. E.(1951). A.M.A. Arch. Ophthal., $45,567$.

Hagedoorn, A., and BosCh, C. van den (1955). Amer. J. Ophthal., 40, 891.

HeRvoü̈T, F. (1958). "Travaux d'anatomie pathologique oculaire", 2me série, pp. 93-127. Masson, Paris.

HuYsmans, J. H. B. M. (1940). Ophthalmologica (Basel), 100, 246.

KLIEN, B. A. (1950). Amer. J. Ophthal., 33, 371. (1958). A.M.A. Arch. Ophthal., 60, 175.

Koyanagi, Y. (1934). v. Graefes Arch. Ophthal., 132, 352.

KURz, O. (1947). Ophthalmologica (Basel), 114, 262.

Renard, G., Dhermy, P., and Amar, L. (1960). Arch. Ophtal., n.s. 20, 797.

Rosehr, K. (1954). Klin. Mbl. Augenheilk., 124, 171.

SorSBY, A. (with a genetic note by Grüneberg, H.) (1940). Brit. J. Ophthal., 24, 469. and CRICK, R. P. (1953). Ibid., 37, 129.

and MASON, J. (with the assistance of GARDENER, N.) (1949). Ibid., 33, 67. and Wren, N. (1960). A.M.A. Arch. Ophthal., 63, 918.

Stargard, K. (1909). v. Graefes Arch. Ophthal., 71, 534. (1913). Z. Augenheilk., 30, 95. (1916). Ibid., 35, 249.

Steinmetz, R. D., Ogle, K. N., and Rucker, C. W. (1956). Amer. J. Ophthal., 42, no. 4,!pt 2, p. 304.

VaIL, D., and SHосн, D. (1959). Trans. Amer. ophthal. Soc., 56, 58.

ZANEN, J. (1953). Bull. Soc. belge Ophtal., No. 104, p. 289. and LEMPEREUR (1954). Ibid., No. 107, p. 296. and Rausin, G. (1950). Ibid., No. 96, p. 544. (1951). Ibid., No. 98, p. 400. 